\title{
Advection flow through sludge flocs
}

\author{
G.W. Tsou, R.M. Wu, P.S. Yen, D.J. Lee* \\ Chemical Engineering Department, National Taiwan University, 10617 Taipei, Taiwan, ROC
}

\begin{abstract}
This work, for the first time, monitored advection flow through the floc interior using a bubble tracking technique. Three sludge flocs were examined, including two original activated sludge flocs and one flocculated floc. Observing the motion of a swarm of hydrogen bubbles passing over a free-falling floc allowed us to estimate the extent of advection flow as over 55\% for all investigated flocs. Polymer flocculation reduced the floc interior permeability and yielded a weak advection flow.
\end{abstract}

(C) 2002 Elsevier Science Ltd. All rights reserved.

Keywords: Advection; Floc; Bubble tracking; Experiments

\section{Introduction}

The hydrodynamic drag force exerted on a floc must be more thoroughly understood to predict its motion (Gregory, 1998). The drag force exerted on a floc depends on several factors, such as drag coefficient (Huang, 1993), primary particle density (Lee, 1994) and the correction factor for advection flow ( $\mathrm{Li}$ and Ganczarczyk, 1988, 1992; Logan and Hunt, 1988). Lee et al. (1996) discussed the current understanding in this issue. Among these factors the role of advection flow has not been satisfactorily explored (Wu and Lee, 1998).

Wu et al. (1998) employed a hydrodynamic approach to estimate the permeability of the floc interior, which controls the extent of the advection flow. Wu et al. observed the motion of a porous floc moving towards an impermeable plate and compared it with that of a non-porous sphere, thus estimating the floc interior permeability for waste activated sludge. Following this idea the permeabilities for polymer flocculated sludge flocs and for fluid sheared flocs were accordingly estimated (Wu et al., 2000a,b). The advection flow through the floc interior affects the capture ratio of fine particles in the suspension by the floc (Logan, 1999).

\footnotetext{
*Corresponding author. Tel.: +886-2-363-5230;

fax: + 886-2-362-3040.

E-mail address: djlee@ccms.ntu.edu.tw (D.J. Lee).
}

Although most literature considering floc processes is based on a significant advection flow, no direct experimental evidence of its existence is available. Consequently, the validity of the advection flow-based works mentioned above cannot be considered justified. This work adopted the bubble-tracking technique to directly observe the advection flow and the nearby, flow-around fluid field of a sludge floc. The radius of the 'fluid tube' that could flow through the floc interior was determined.

\section{Bubble tracking technique}

Consider a porous sphere with radius $R$ falling freely in an infinitely large Newtonian fluid pool. Under the sphere is a fluid tube with radius $\omega$ within which the fluid flows through the sphere, while outside this tube the fluid flows around the sphere (Fig. 1). Clearly, for an impermeable sphere $\omega / R=0$, no fluid could flow through the sphere. At another extreme, for 'no sphere', or a sphere with infinitely large permeability, $\omega / R \rightarrow$ 1.0 , fluid could only flow around the sphere. For a porous sphere with permeability $k, \omega / R$ would range between 0 and 1 , depending on the ease of fluid flow through the sphere. As Fig. 1 displays, the fluid particles originally existing at position of $\left(\mathrm{X}_{1}, \mathrm{Y}_{1}\right)$ would sweep over the sphere surface at position $\left(\mathrm{X}_{2}, \mathrm{Y}_{2}\right)$. The basic idea adopted herein is that estimating the dimensionless 


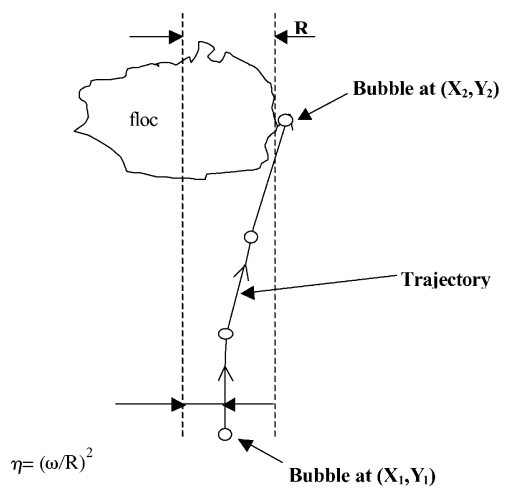

Fig. 1. Fluid tube and falling floc.

permeability depends on estimating the dimensionless permeability.

The bubble tracking technique was employed herein to estimate the capture ratio of the sludge flocs. A swarm of bubbles were released from the bottom of a pool and rose along the centerline of the falling floc. Since the bubbles are small (normally less than $5 \mu \mathrm{m}$ in diameter), they basically follow the streamline of the fluid. Observing the interaction between the floc and the bubbles provides useful information regarding the fluid field and capture ratio.

\section{Experimental}

Waste activated sludge sample was taken from the wastewater treatment plant in Neili Bread Plant, Presidental Enterprise Co., Taoyuan, Taiwan, and was tested within $2 \mathrm{~h}$ of sampling. The chemical oxygen demand (COD), suspended solids (SS) and turbidity data were for the supernatant drawn from the sludge, determined using EPA Taiwan standard methods. The results were as follows: $5.6 \mathrm{mg} / 1$ (COD), $7.1 \mathrm{mg} / 1$ (SS) and 1.4 NTU (turbidity). The weight percentage of the sludge sample was $0.7 \%(\mathrm{w} / \mathrm{w})$. The solid density data of the sludges was measured using Accupyc Pycnometer 1330 (Micromeritics) as being approximately $1450 \mathrm{~kg} / \mathrm{m}^{3}$. The zeta meter (Zetasizer 200, Marlvern) measured the zeta potential of the original sludge flocs as being -16 mV. Cationic flocculant, T-3052 from Kai-Kuan Corp., Taiwan, was employed for sludge conditioning. Meanwhile, cationic polyelectrolyte flocculant, indicated as being polymer T-3052, was obtained from Kai-Guan Inc., Taiwan. The polymer T-3052 is a cationic polyacrylamide with an average molecular weight of $10^{7}$ and a charge density of $20 \%$. Finally, the mixing unit was a baffled mixing chamber with a stirrer. The weighed sludge was first placed into the mixing chamber, and polymer solution was gradually poured in and stirred at
$200 \mathrm{rev}$. $/ \mathrm{min}$ for $5 \mathrm{~min}$ followed by $50 \mathrm{rev}$. $/ \mathrm{min}$ for another $20 \mathrm{~min}$.

Fig. 2 schematically depicts the testing apparatus. A glass tank $[10 \mathrm{~cm}(\mathrm{l}) \times 10 \mathrm{~cm}(\mathrm{~W}) \times 30 \mathrm{~cm}(\mathrm{H})]$ was used to test floc-settling. A floc is released carefully from the top of the column and settled at a terminal velocity of $V_{t}$. Two plates with central holes were placed in the settling tube. The plates screen out flocs that do not move along the central line. Close to the tank bottom a platinum wire with a diameter of $35 \mathrm{~mm}$ was hung across the centerline of the tank to serve as the cathode, and was connected to a pulse generator (Bubble Generator, MN-305, Sugawara, Japan). The anode was positioned near the top of the tank, and thus did not interfere with the floc motion. The pulse generator produced electrical pulses at intervals of $5 \mathrm{~ms}$, and thus yielded chains of tiny hydrogen bubbles that rose from the cathode. Two digital cameras, JAI 950 1/3" (JAI, 210 pixels in $1 \mathrm{~mm}$ ) and NEC TC-22A (130 pixels in $1 \mathrm{~mm}$ ), both equipped with a close-up lens (MML2110D) recorded the floc motion. The images were recorded and sent continuously to a workstation. The whole alignment was adjusted to the meetings between the settling floc and rising bubble chains within the window for observation.

The images were analyzed using Software Inspector V2.2 (Matrox). The cross-sectional area of the floc was recorded, along with the Feret diameters along the horizontal $\left(F_{x}\right)$ and vertical $\left(F_{y}\right)$ axes. The center of the floc was fixed at the mid-point of the two Feret diameters. The data on the positions of floc center vs. time allowed the settling velocity of floc $\left(V_{f}\right)$ to be

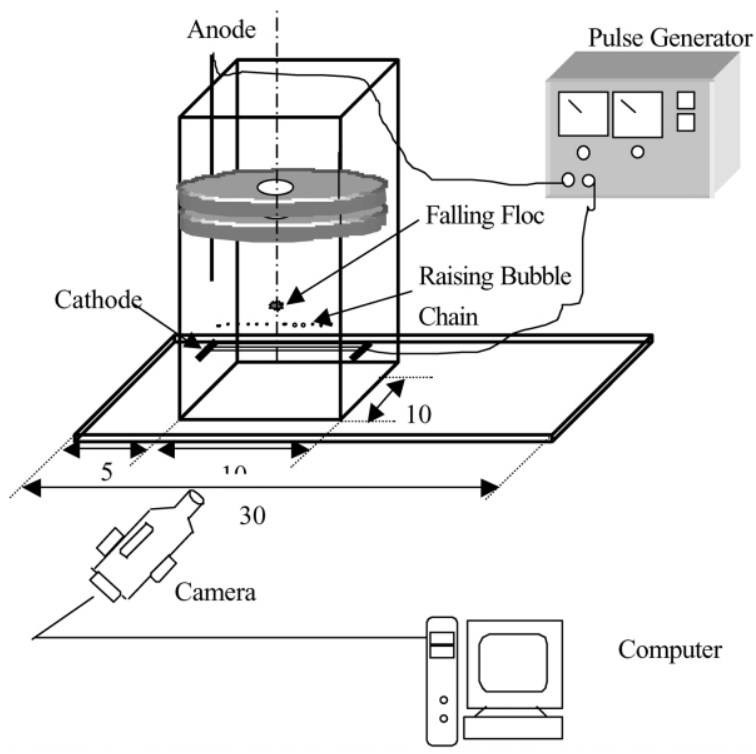

Fig. 2. Experimental setup. 


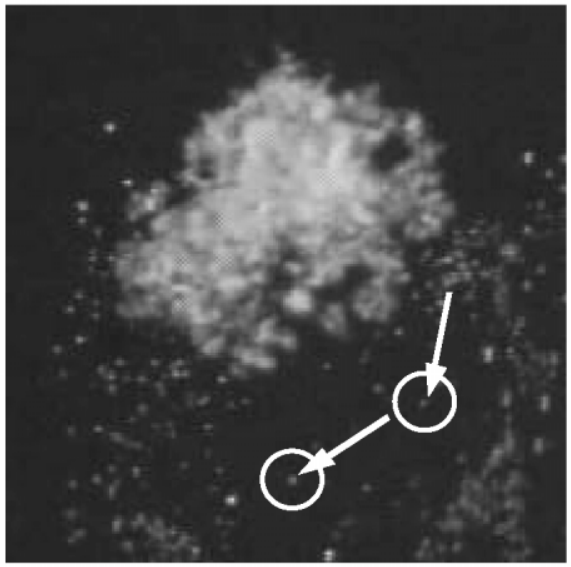

(a)

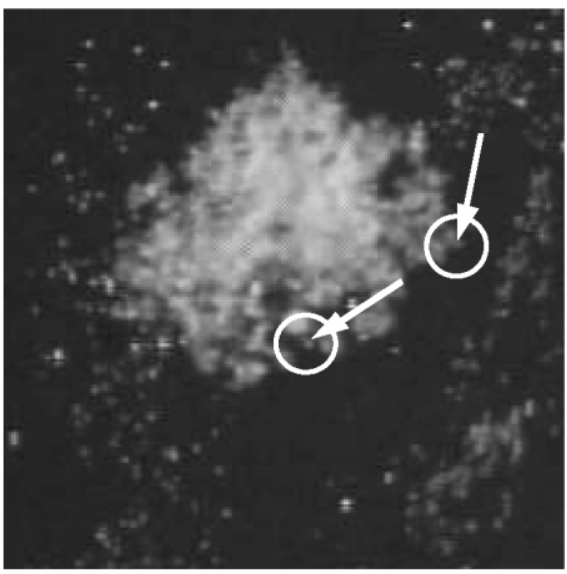

(c)

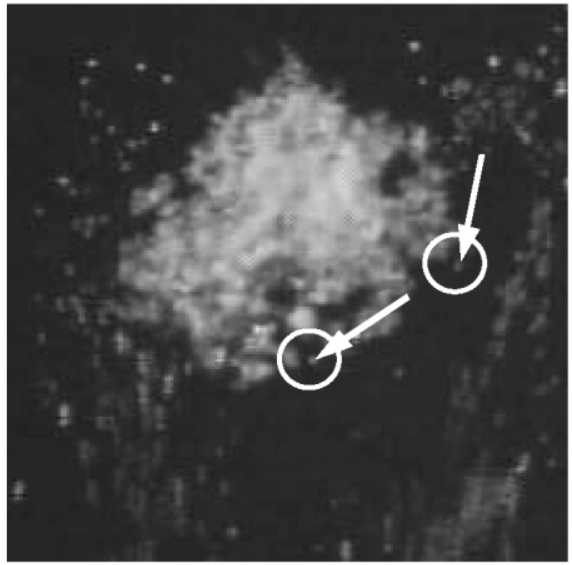

(b)

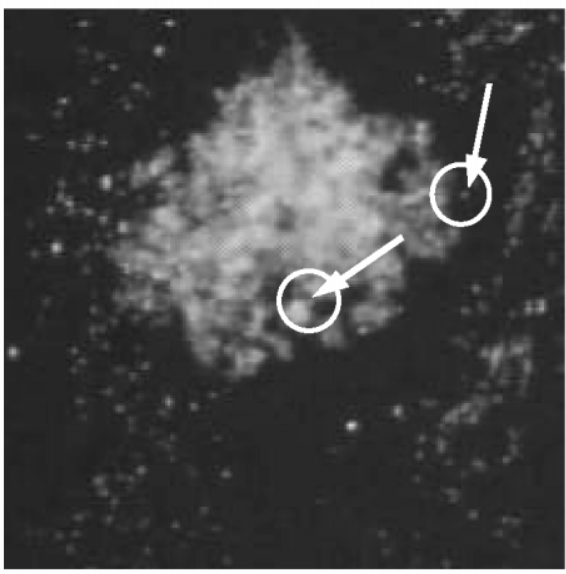

(d)

Fig. 3. Tracking of bubbles and falling floc. Floc A2.

estimated using numerical smoothing and differentiation.

\section{Results and discussion}

\subsection{Visual observations}

Fig. 3 presents a portion of the microphotographs of the original floc A2 (diameter $1,026 \mu \mathrm{m}$ ) while interacting with the rising bubbles. The floc interior is rather loose and can be seen through. The terminal velocity of floc A1 before it interacts with the rising bubbles is measured as $0.34 \mathrm{~mm} / \mathrm{s}$, giving a Reynolds number of 0.35 .

Fig. 3a illustrates the falling floc and a few rising bubbles from the first bubble chain. The bubbles indi- cated by the arrow are located just beneath the floc. These bubbles exhibit a rising terminal velocity of 0.13 $\mathrm{mm} / \mathrm{s}$ when they are still far away from the floc. In Fig. $3 b$, which displays the situation $0.42 \mathrm{~s}$ after Fig. $3 \mathrm{a}$, the indicated bubbles have penetrated the floc and are trapped there. This phenomenon indicates that the floc interior is indeed highly permeable and thus open to fluid flow (the advection flow). Consequently, the hypothesis supporting advection flow in the literature works is justified for the first time. Afterward, in Fig. $3 \mathrm{c}, \mathrm{d}$, more bubbles penetrate into the floc (the arrow as seen in the figure indicates the bubble discussed above).

Fig. 4 displays the response of a typical flocculated floc P2 (diameter of $1,850 \mu \mathrm{m}$ ) as it interacts with the rising bubbles. Experimental observations noted that the response of most flocculated sludge flocs resemble that 
of floc P4. Apparently, the interior of the floc is denser than floc A2. The $V_{t}$ of $\mathrm{P} 2$ is $3.69 \mathrm{~mm} / \mathrm{s}$, which is 10 times greater than A2. Fig. 4a presents the falling floc and rising bubbles. The bubbles indicated by the arrow approach the floc bottom. In Fig. 4b, the falling floc falls at a velocity close to the terminal velocity. Meanwhile, some bubbles penetrate the floc while the remainders are pushed away (Fig. 4c,d).

\subsection{Extent of advection flow}

The relative positions of the rising bubbles to the floc could be obtained by simply subtracting the position vectors of the bubbles from that of the floc for different times. The streamline just sweeps over the floc surface [positions $\left(\mathrm{X}_{1}, \mathrm{Y}_{1}\right)$ and $\left(\mathrm{X}_{2}, \mathrm{Y}_{2}\right)$ in Fig. 1] is of particular interest. This information, together with the
Table 1

Floc characteristics

\begin{tabular}{lllll}
\hline ID number & $\begin{array}{l}\text { Diameter } \\
(\mathrm{mm})\end{array}$ & $\begin{array}{l}V_{t} \\
(\mathrm{~mm} / \mathrm{s})\end{array}$ & $R \mathrm{e}_{\mathrm{t}}$ & $\begin{array}{l}(\omega / R)^{2} \\
(-)\end{array}$ \\
\hline $\mathrm{A} 2$ & 1.03 & 0.34 & 0.35 & 0.67 \\
$\mathrm{~A} 6$ & 0.91 & 1.11 & 1.00 & 0.74 \\
$\mathrm{P} 2$ & 1.85 & 3.69 & 6.80 & 0.55 \\
\hline
\end{tabular}

floc radius data, yields the dimensionless cross-sectional area of the fluid tube $(\omega / R)^{2}$, or the extent of the advection flow. Table 1 also lists these results.

Approximately $55-76 \%$ of the approaching fluid flows through rather than flows around the investigated flocs. The role of advection flow is significant and cannot be neglected. Although with limited data only,

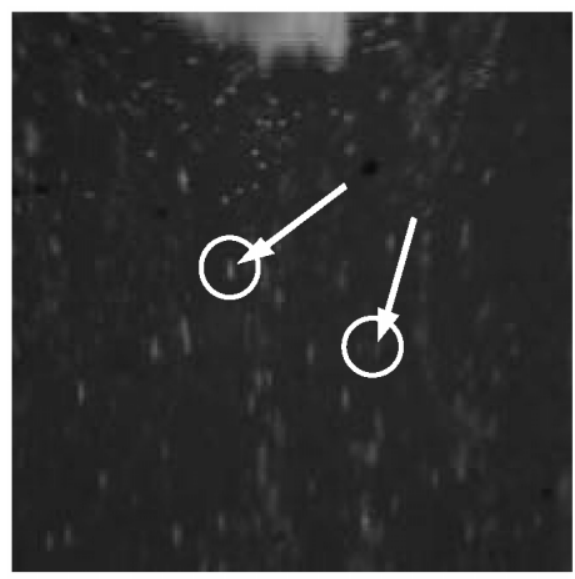

(a)

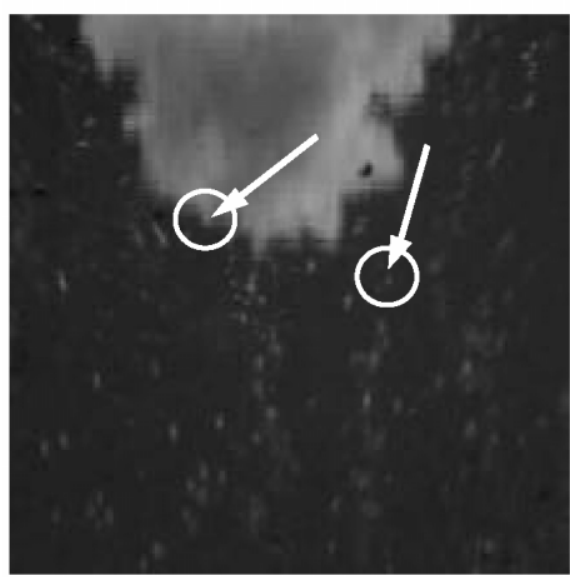

(c)

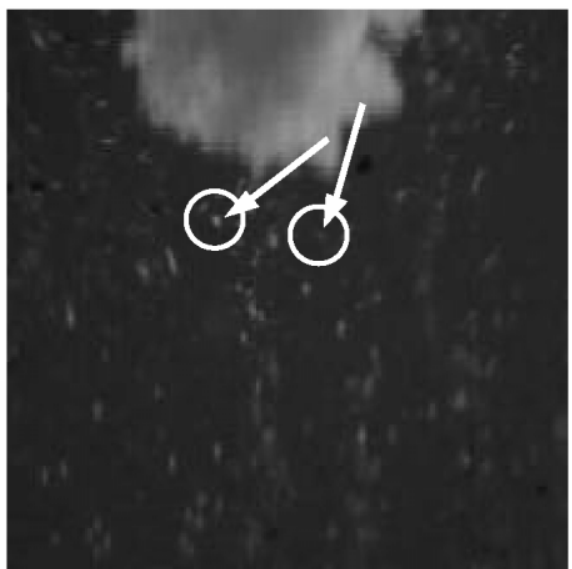

(b)

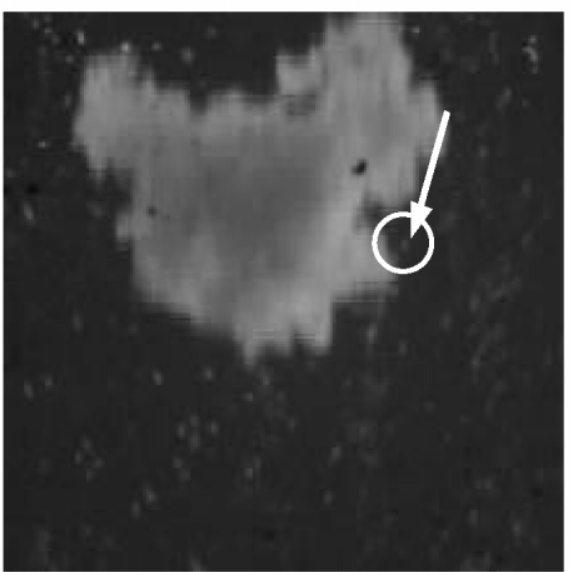

(d)

Fig. 4. Tracking of bubbles and falling floc. Floc P2. 
the extent of advection flow is demonstrated to be higher for original flocs $(67-76 \%)$ than the flocculated floc $(55 \%)$. Restated, the application of polymer for flocculation yields a more compact floc interior and hence a less extent of advection flow. There may not exist a simple correlation between floc size and permeability. For instance, the size of floc A6 resembles that of A2, however, exhibits a much faster terminal velocity $(1.11 \mathrm{~mm} / \mathrm{s})$ than the latter $(0.34 \mathrm{~mm} / \mathrm{s})$. On the other hand, the extent of advection flow is higher for the former than the latter. Therefore, the density of primary particles, and other factors come into play for determining the terminal velocity.

\section{Conclusions}

This investigation directly observed the fluid field surrounding sludge flocs and noted the existence of advection flow through the floc interior. Observing the interactions between the motion of the free-falling floc and the rising bubbles revealed that over $55 \%$ of the approaching fluid flowed into the interior of an activated sludge floc. This observation justified the advection flow-based literature works.

\section{Acknowledgments}

National Science Council, R.O.C. financially supported this research.

\section{References}

Gregory, J., 1998. The role of floc density in solid-liquid separation. Filtration and Separation, May, 367-371.

Huang, H., 1993. Porosity-size relationship of drilling mud flocs: fractal structure. Clay Clay Miner. 41, 373-379.

Lee, D.J., 1994. Floc structure and bound water content in excess activated sludges. J. Chin. Inst. Chem. Engrs. 25, 201-207.

Lee, D.J., Chen, G.W., Liao, Y.C., Hsieh, C.C., 1996. Use of free-settling test to estimate activated sludge flocs density. Water Res. 30, 541-550.

Li, D.H., Ganczarczyk, J., 1988. Flow through activated sludge flocs. Water Res. 22, 789-792.

Li, D.H., Ganczarczyk, J., 1992. Advective transport in activated sludge flocs. Water Environ. Res. 64, 236-240.

Logan, B.E., Hunt, J.R., 1988. Biofloccuation as microbial response to substrate limitation. Biotechnol. Bioeng. 31, 92-101.

Logan, B.E., 1999. Environmental Transport Processes. John Wiley \& Sons, Inc, New York.

Wu, R.M., Feng, W.H., Tsai, I.H., Lee, D.J., 1998. An estimate of waste activated sludge floc permeability: a novel hydrodynamic approach. Water Environ. Res. 70, 1258-1264.

Wu, R.M., Lee, D.J., 1998. Hydrodynamic drag force exerted on a moving floc and its implications to free settling test. Water Res. 32, 860-868.

Wu, R.M., Tsou, G.W., Lee, D.J., 2000a. Estimate of sludge floc permeability. Chem. Eng. J. 80, 37-42.

Wu, R.M., Tsou, G.W., Lee, D.J., 2000b. Estimation of the interior permeability of polymer-flocculated sludge flocs. Adv. Environ. Res. 4, 163-167. 